\title{
Thermal Vacuum Test Performance of the Hubble Space Telescope (HST) Wide Field Camera 3 (WFC3) Variable Conductance Heat Pipe Assembly
}

\author{
Paul E. Cleveland \\ Energy Solutions International, L.L.C. \\ Matthew T. Buchko \\ Swales Aerospace, Inc. \\ Richard A. Stavely \\ NASA / Goddard Space Flight Center
}

Copyright (C) 2003 SAE International

\begin{abstract}
The Variable Conductance Heat Pipe (VCHP) Assembly of the HST Wide Field Camera 3 was subjected to thermal vacuum (T/V) environmental testing. The test program included both maximum and minimum environments as well as simulated on-orbit cycling. Elements of the VCHP assembly included a VCHP, an optical bench cold plate with an imbedded constant conductance heat pipe, and a VCHP reservoir radiator with a proportionally controlled heater.
\end{abstract}

The purpose of the test was to characterize and demonstrate the assembly's ability to control the temperature of the cold plate, which provides a stable thermal environment for the instrument's optical bench.

This paper discusses the VCHP Assembly control performance and control authority during the dynamic hot and cold 90-minute orbit cycling test phases.

\section{INTRODUCTION}

The Hubble Space Telescope (HST) is one of the National Aeronautics and Space Administration's (NASA) premier astronomical observatories. A unique design feature of the spacecraft is its capacity to be serviced and refurbished on-orbit. Repairs to the HST are made during events called Servicing Missions (SM). The SM consists of several phases that include: shuttle launch, ascent, rendezvous with HST, grapple, Extra Vehicular Activity (EVA) servicing, redeployment of the HST, shuttle entry and landing. The purpose of a SM is to upgrade the HST scientific capabilities and to repair or replace failed equipment. The benefit of the SM is to enhance the scientific capability of the HST and to extend its operational lifetime to a decade or more.
Servicing Mission 4 (SM-4) is currently scheduled for 2005. During one of the five EVA days, the crew will replace the Wide Field Planetary Camera II (WFPCII) with the Wide Field Camera 3 (WFC3). The HST slot for these instruments is the "-V3 Radial Instrument" position.

The WFC3 contains both Ultraviolet and Infrared detectors. Due to the differing thermal requirements for these items and their associated assemblies, the WFC3 contains several thermal subsystems within the instrument enclosure. Figure 1 shows the instrument enclosure and identifies some of the thermal control hardware. (The instrument optical bench has been removed for clarity). One of these subsystems is the Variable Conductance Heat Pipe (VCHP) assembly.

Figure 1 WFC3 Enclosure with VCHP Assembly

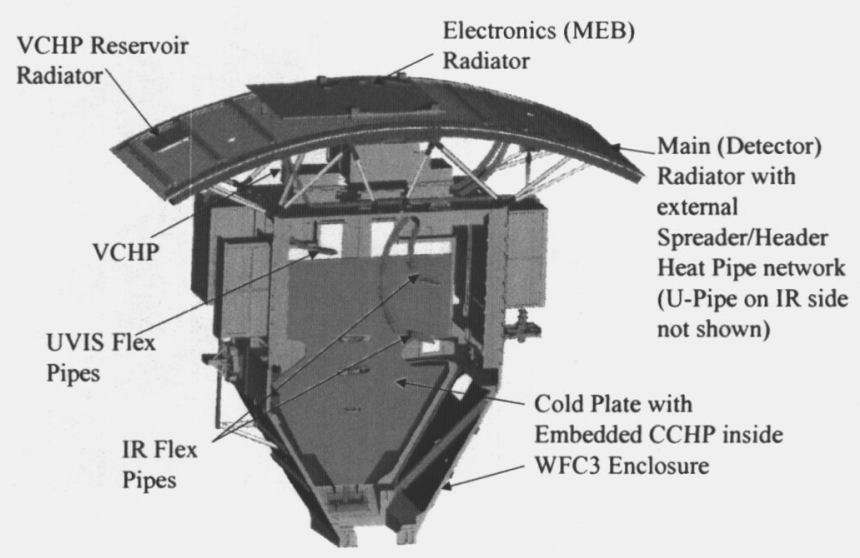

As a radial instrument, the WFC3 sees an HST internal thermal environment that ranges from $13^{\circ} \mathrm{C}$ to $20^{\circ} \mathrm{C}$. This environment, however, is too warm for the IR 
Detector components. The preferred temperature for the IR optical components is $0^{\circ} \mathrm{C}$. The instrument Optical Bench Assembly (OBA), which houses the IR optics, is thus cooled to $0^{\circ} \mathrm{C}$ by placing a radiative heat sink or Cold Plate under the OBA. The Cold Plate is maintained at $-5^{\circ} \mathrm{C}$. The Cold Plate, in turn, is coupled to the external radiator. Since the radiator orbital temperature variations do not provide a stable heat sink, a variable thermal coupling to the radiator is required. The actively controlled VCHP Assembly provides this variable coupling.

The VCHP assembly consists of the Optical Bench Cold Plate (OBCP), which contains an imbedded constant conductance heat pipe (CCHP); a variable conductance heat pipe; and a VCHP reservoir radiator (offset and thermally decoupled from the main WFC3 external radiator). The reservoir radiator, which regulates the reservoir gas temperature, uses a proportionally controlled heater system. The VCHP condenser utilizes the main WFC3 external radiator to reject its heat to space. The OBCP and the OBA are jointly wrapped in a Multi Layer Insulation (MLI) enclosure.

The primary challenge for the VCHP assembly is to maintain the OBCP at $-5^{\circ} \mathrm{C} \pm 2^{\circ} \mathrm{C}$ for various heat loads while subject to a 90 -minute orbit cycling environment which ranges from $0^{\circ} \mathrm{C}$ to $-143^{\circ} \mathrm{C}$.

This paper discusses the VCHP Assembly control performance during the dynamic hot and cold, 90-minute orbit cycling test phases. These phases are of particular interest because they demonstrate the control authority of the assembly. The test was conducted in Chamber \#237 at the NASA/Goddard Space Flight Center (GSFC). It lasted approximately fourteen days, from 5-28-02 to 610-02.

\section{TEST OVERVIEW}

Figure 2 shows the overall test profile. Table 1 identifies the various test phases. As shown, there were sixteen discreet cases. This paper addresses Case 5, "Cold Cycling", and Case 10, "Hot Cycling". These two cases were of particular interest because they bracket the dynamic operational requirements of the assembly from a power and an environmental perspective.

Table 1: Summary of Thermal Vacuum Test Phases

\begin{tabular}{|c|l|}
\hline $\begin{array}{c}\text { Phase } \\
\#\end{array}$ & \multicolumn{1}{|c|}{ Description } \\
\hline 1 & Pumpdown \\
\hline 2 & Post Insertion Cold Case \\
\hline 3 & Cold Balance \\
\hline 4 & Minimum Radiator Temperature / Capacity Test \\
\hline 5 & Cold Cycling \\
\hline 6 & Cold Decontamination \\
\hline 7 & Hot Balance \\
\hline 8 & Maximum Radiator Temperature / Capacity Test \\
\hline 9 & Post Insertion Hot Case \\
\hline 10 & Hot Cycling \\
\hline 11 & Return to Ambient \\
\hline 12 & Remove all MLI \\
\hline 13 & Pumpdown \\
\hline 14 & Bakeout \\
\hline 15 & Contamination Certification \\
\hline 16 & Return to Ambient \\
\hline
\end{tabular}

Figure 2: VCHP TN Test Profile

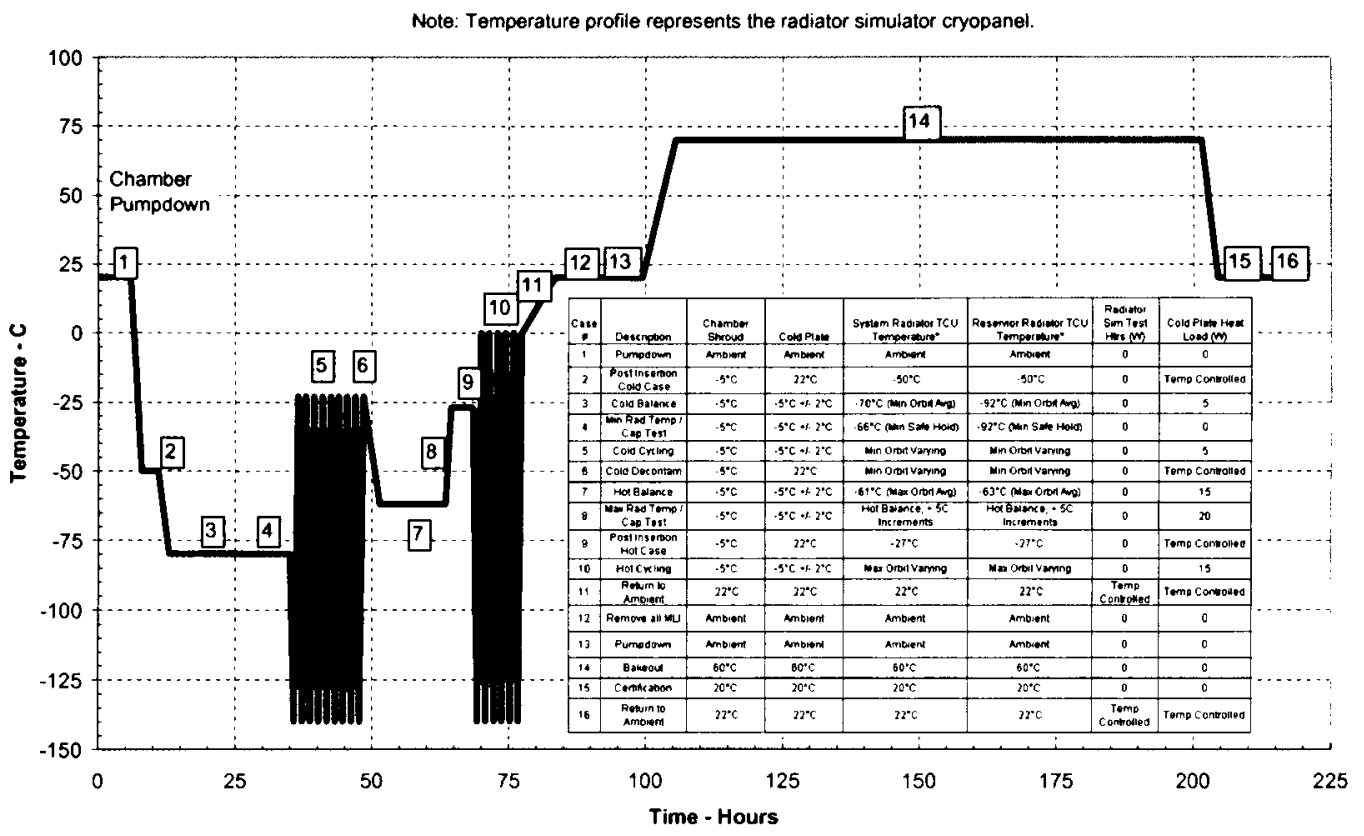




\section{TEST OBJECTIVES}

Table 2 lists the test objectives for the entire test. Each objective served to characterize the VCHP performance and capacity for a specific flight-like environment.

\section{Table 2: VCHP Test Objectives}

\begin{tabular}{|l|l|}
\hline$\#$ & \multicolumn{1}{|c|}{ Test Objectives } \\
\hline 1 & $\begin{array}{l}\text { Demonstrate adequate system performance in hot } \\
\text { balance condition. (Hot flight environment). } \\
\text { Maximum heat load. Maintain system cold-plate at } \\
-5^{\circ} \mathrm{C} \pm 2^{\circ} \mathrm{C} \text {. }\end{array}$ \\
\hline 2 & $\begin{array}{l}\text { Demonstrate adequate system performance in cold } \\
\text { balance condition. (Cold flight environment). } \\
\text { Minimum heat load. Maintain system cold-plate at } \\
-5^{\circ} \mathrm{C} \pm 2^{\circ} \mathrm{C} \text {. }\end{array}$ \\
\hline 3 & $\begin{array}{l}\text { Provide sufficient information at the cold and hot } \\
\text { balance conditions to allow thermal model } \\
\text { correlation. }\end{array}$ \\
\hline 4 & $\begin{array}{l}\text { Demonstrate ability of VCHP heater to shutdown } \\
\text { the condenser in the cold case. Per GEVS, there } \\
\text { should be at least } 30 \% \text { heater power margin. }\end{array}$ \\
\hline 5 & $\begin{array}{l}\text { Demonstrate control authority of system when } \\
\text { subjected to a simulated cold worst-case orbit- } \\
\text { varying sink i.e., time varying sink. Maintain system } \\
\text { cold-plate at }-5^{\circ} \mathrm{C} \pm 2^{\circ} \mathrm{C} \text {. }\end{array}$ \\
\hline 6 & $\begin{array}{l}\text { Demonstrate control authority of system when } \\
\text { subjected to a simulated hot worst-case orbit- } \\
\text { varying sink i.e., time varying sink. Maintain system } \\
\text { cold-plate at }-5^{\circ} \mathrm{C} \pm 2^{\circ} \mathrm{C} \text {. }\end{array}$ \\
\hline 7 & $\begin{array}{l}\text { Measure temperature gradient along VCHP } \\
\text { condenser during cold and hot cases. }\end{array}$ \\
\hline 8 & $\begin{array}{l}\text { Characterize joint and interface conductances at } \\
\text { key heat transfer paths along the system. (Cold } \\
\text { Plate to CCHP, CCHP to VCHP saddle assembly, } \\
\text { condenser to system radiator, reservoir to reservoir- } \\
\text { radiator, reservoir-radiator to system radiator). }\end{array}$ \\
\hline 9 & $\begin{array}{l}\text { Characterize throughput conductance i.e., end-to- } \\
\text { end conductance, of the system. }\end{array}$ \\
\hline 10 & $\begin{array}{l}\text { Demonstrate hot start capability of the thermal } \\
\text { system. }\end{array}$ \\
\hline 11 & $\begin{array}{l}\text { Demonstrate cold start capability of thermal system } \\
\text { at cold mission extremes as well as at survival } \\
\text { limits. }\end{array}$ \\
\hline 12 & $\begin{array}{l}\text { Verify proper workmanship and operation of all } \\
\text { components when integrated as a system. }\end{array}$ \\
\hline 13 & $\begin{array}{l}\text { Conduct a maximum radiator temperature / } \\
\text { capability test. }\end{array}$ \\
\hline 14 & $\begin{array}{l}\text { Conduct a minimum radiator temperature I } \\
\text { capability test. }\end{array}$ \\
\hline
\end{tabular}

\section{TEST CONFIGURATION}

Figures 3 and 4 illustrate the TN chamber setup. Figures 5 and 6 show the Flight Thermistor, Heater and FET Layout for the OBCP and VCHP Assembly, respectively. Appendix A provides photographs. Table 3 identifies the 13 Flight Thermistors. As noted below, the test configuration included: flight hardware, test simulator hardware, and Ground Support Equipment (GSE). Major elements included:

- The flight optical bench cold plate with an integral CCHP. All flight thermal control hardware - heaters, FETs and thermistors were installed. See Figure 5. The 25-watt, dual-element flight heater was controlled via the test power supplies in order to provide the appropriate heat load. The power supplies had the capability to provide both temperature control and heater flux control.

- The flight VCHP system including flight thermistors. See Figure 6.

- The flight reservoir radiator with flight heaters, FETs, and thermistors. A GSE set-point commandable proportional controller drove the 10-watt heater system, which consisted of two 5-watt, dual-element heaters. The dual elements provide redundancy.

Figure 3. Test Configuration in Chamber 237

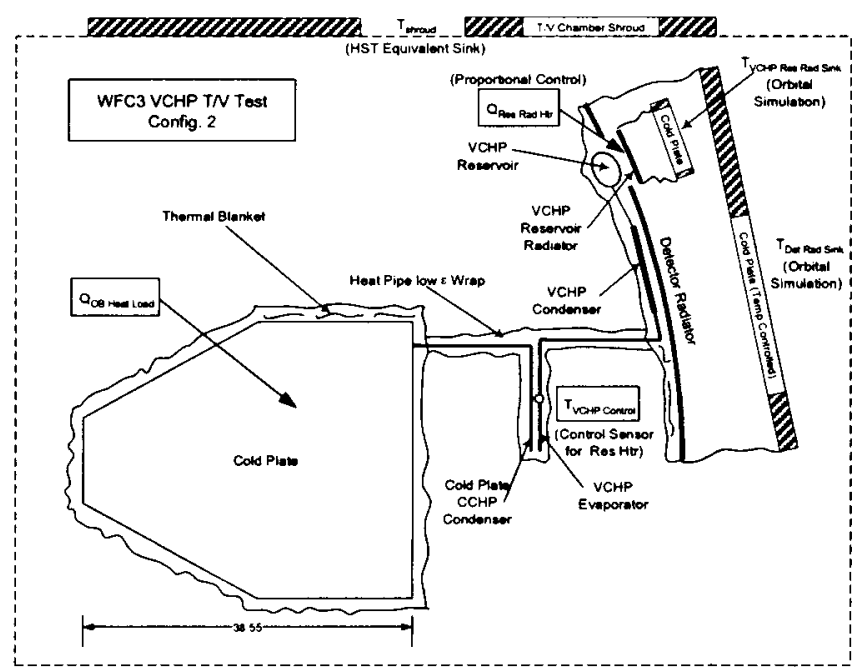

Figure 4 Test Layout in Chamber 237.

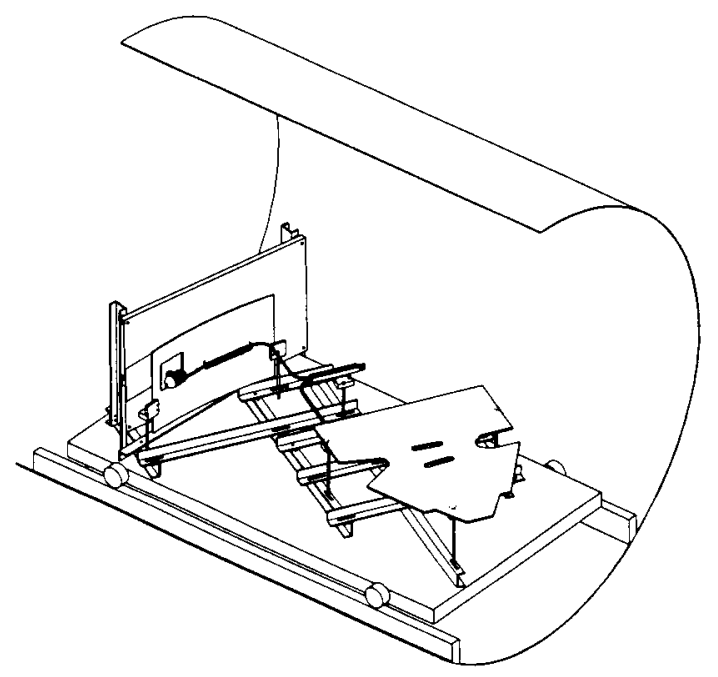


- A test simulator of the WFC3 external radiator.

- Thermal Vacuum Chamber \#237 at Goddard Space Flight Center. This chamber had a standard feed thru for the thermocouples and heater wires.

- Power Supplies and a Proportional Heater Controller delivered current limited power to the flight heaters on the cold plate and reservoir radiator. A current sensor around the power leads determined the current supplied to the board.

- The Thermal Vacuum Data Acquisition System conditioned the signals from the test thermocouples.

- Temperature Control Units (TCU's) regulated the chamber cryopanel temperatures, which provided boundary temperatures for the two radiators. Two separate cryopanels were used because the two radiators had different thermal control coatings and required different equivalent sink temperatures.

- Multi-layer Insulation provided the necessary thermal isolation.

\section{PROPORTIONAL CONTROL}

The VCHP temperature control of $-5^{\circ} \mathrm{C} \pm 2^{\circ} \mathrm{C}$ is achieved through the use of a proportionally controlled heater zone. This system utilizes a ground programmable electronic thermostat to provide regulated power to the reservoir radiator heaters.

The software control algorithm is a proportional function that compares signals from the control temperature sensors located remotely on the VCHP evaporator with the set-point temperature. The power is then regulated to the reservoir radiator heaters, which control the reservoir non-condensable gas (Nitrogen) temperature. The temperature of the gas determines the gas volume in the condenser and the condenser length available for the VCHP ammonia working fluid. Controlling the effective condenser length regulates the ammoniasaturated temperature and the amount of heat rejected at the system radiator

Table 3. Flight Thermistors

\begin{tabular}{|c|l|c|}
\hline $\begin{array}{c}\text { Thermistor } \\
\#\end{array}$ & \multicolumn{1}{|c|}{ Location } & Mnemonic \\
\hline 1 & $\begin{array}{l}\text { Thermistor (07) - VCHP } \\
\text { Condenser Saddle }\end{array}$ & ICPCONDT-A \\
\hline 2 & $\begin{array}{l}\text { Thermistor (07) - VCHP } \\
\text { Condenser Saddle }\end{array}$ & ICPCONDT-B \\
\hline 3 & $\begin{array}{l}\text { Thermistor (03) - VCHP } \\
\text { Reservoir Radiator }\end{array}$ & IVCHPRT-A \\
\hline 4 & $\begin{array}{l}\text { Thermistor (03) - VCHP } \\
\text { Reservoir Radiator }\end{array}$ & IVCHPRT-B \\
\hline 5 & $\begin{array}{l}\text { Thermistor (09) - VCHP } \\
\text { Evaporator }\end{array}$ & IREST1 \\
\hline 7 & $\begin{array}{l}\text { Thermistor (09) - VCHP } \\
\text { Evaporator }\end{array}$ & IREST2 \\
\hline 9 & Thermistor (07) - Cold Plate & ICPLATET-A \\
\hline 10 & Thermistor (07) - Cold Plate & ICPLATET-B \\
\hline 11 & Thermistor (09) - Cold Plate & ICPCTRT1 \\
\hline 13 & Thermistor (09) - Cold Plate & ICPCTRT2 \\
\hline
\end{tabular}

Figure 5. Cold Plate Flight Thermistor, Heater and FET Layout

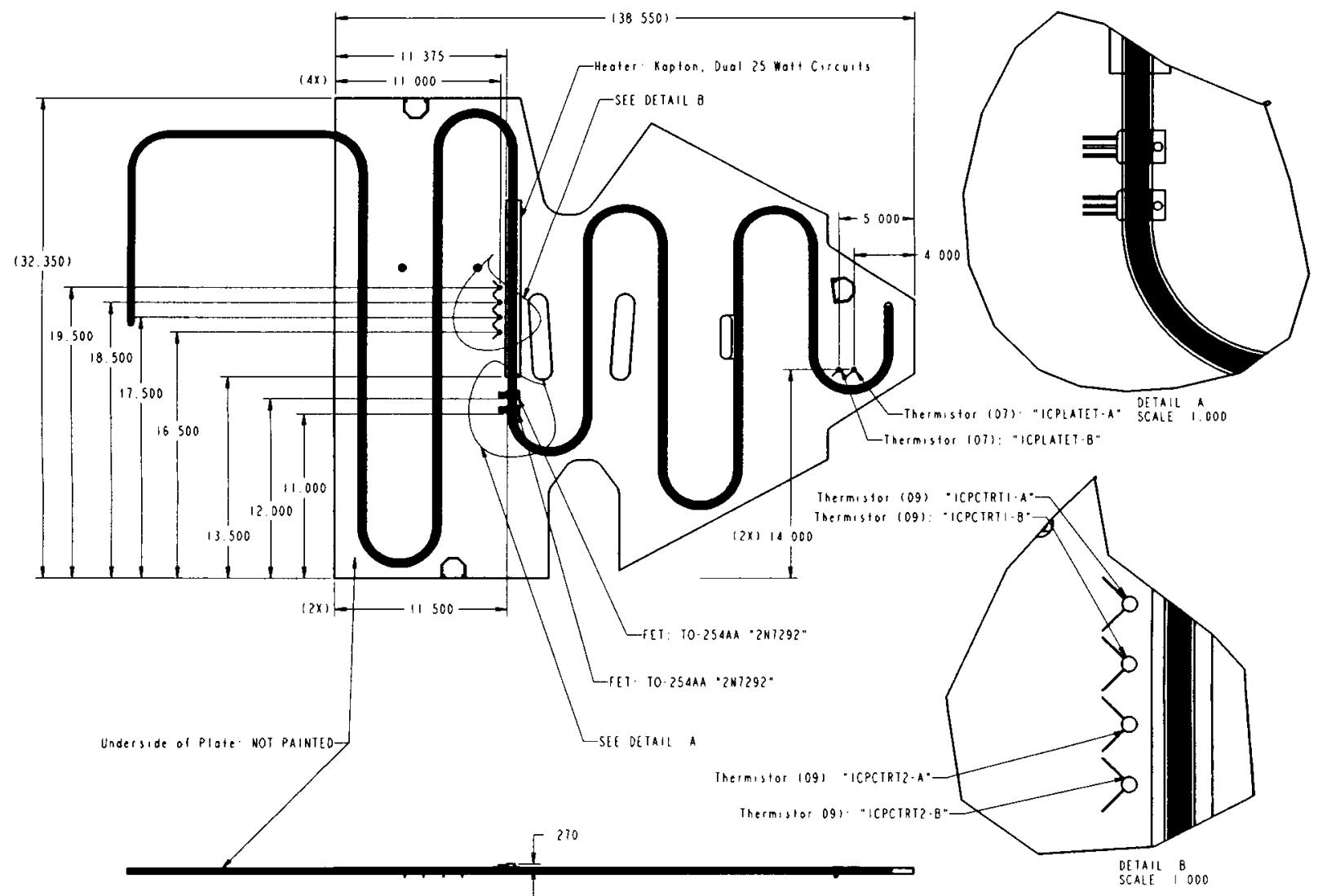




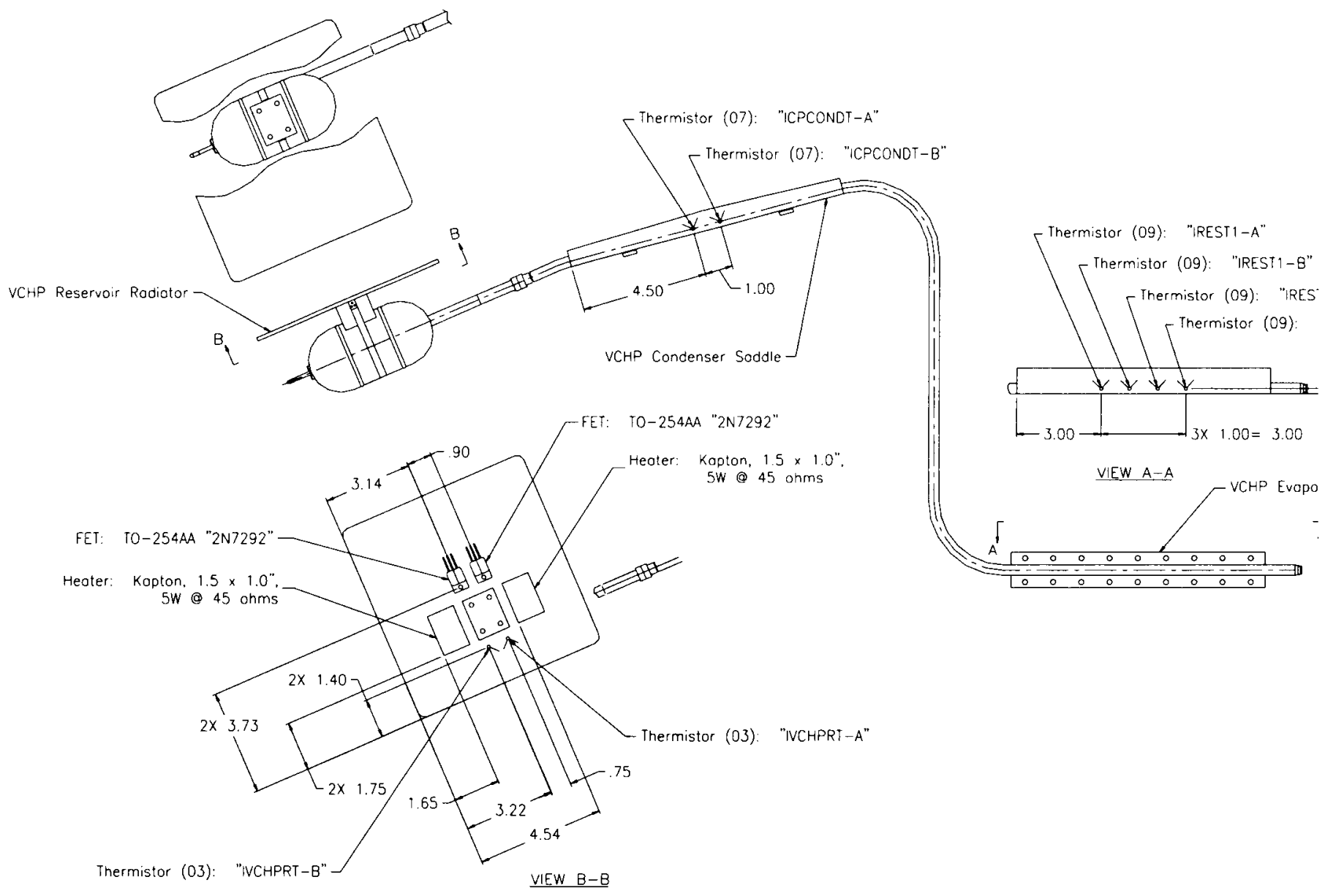

For each heater zone, there are two redundant control circuits, one operating from power supplied by Low Voltage Power Supply (LVPS) 1, and one operating from power supplied by LVPS 2. Two control thermistors in each zone measure the zone temperature and are wired so that they are averaged in the control circuitry. Both the controllers and the thermistors are redundant.

Proportional heater controllers can dissipate a significant amount of power-up to $25 \%$ of the total power available to the zone. Therefore, the main power dissipater in the controller, the FET, is located near the heater so that the dissipated heat is not wasted.

The OBCP also utilizes the same type of proportionally controlled heater zone. This zone, however, is not used for stability control. During the test, it served to provide a heat load on the cold plate for various test cases. In flight, one function of this zone is to raise the temperature of the optical bench to protect it during contamination sensitive periods.

\section{COLD CYCLING RESULTS}

\section{BACKGROUND / PURPOSE}

The Cold Cycling Case was run to demonstrate the control authority of the system when subjected to a simulated cold worst-case orbit-varying sink i.e., time varying sink, with a minimum cold plate heat load of five watts. The system success criteria was to maintain the $\mathrm{OBCP}$ average temperature at $-5^{\circ} \mathrm{C} \pm 2^{\circ} \mathrm{C}$.

To simulate the cold on-orbit environment, transient equivalent sink temperatures were generated from the spacecraft environmental flux studies. These were then adjusted to account for the test configuration effects. For the cold case, the temperature goal was to reach approximately $-20^{\circ} \mathrm{C}$ to $-160^{\circ} \mathrm{C}$ over a 90 -minute period. Two separate cryopanels were necessary due to the different thermal control coatings on the two radiators.

To achieve the minimum sink temperatures, the TCU's provided chilled gaseous Nitrogen. For the maximum sink temperature levels, cryopanel temperature control 
was achieved via heated gaseous Nitrogen and test heaters located on the back of the panels.

\section{SUMMARY OF RESULTS}

For the cold cycling test, the OBCP heater was operated in flux mode and set to the design load of five watts. The reservoir radiator cryopanel and radiator simulator cryopanel were initially set to $-155^{\circ} \mathrm{C}$ and $-165^{\circ} \mathrm{C}$, respectively. The entire cycling process lasted from $5 / 29 / 0215: 35$, to $5 / 30 / 0205: 00$. The goal was to get three repeatable 90 -minute cycles.

The initial cycles reflected efforts to understand the dynamics of the cryopanels and system. The focus was to determine the appropriate TCU set points, necessary cryopanel heater values, and the timing of TCU set-point changes. Challenges included the discovery that the reservoir radiator cryopanel heaters were not functional, and that the two TCU's shared the same LN2 line as a cold sink resulting in them robbing $L N 2$ from each other.

The three repeatable cycles started at 5/29/02 23:49. Figure 7 and Table 4 show key results. In Figure 7, the left hand axis shows temperature and the right hand scale is heater power. As shown, the cryopanel equivalent sink radiators successfully cycled from $-23^{\circ} \mathrm{C}$ to $-143^{\circ} \mathrm{C}$ in a repeatable 90 -minute period. During these cycles, the reservoir radiator heater power ranged from two to six watts. The available power was $10 \mathrm{~W}$. The average cold plate temperature was controlled to a nearly constant level of $-5.7^{\circ} \mathrm{C}$, which was within the required $-5^{\circ} \mathrm{C} \pm 2^{\circ} \mathrm{C}$ temperature range.

As Table 4 indicates, the system more than adequately demonstrated control authority. The orbit average Reservoir Heater power was $4.5 \mathrm{~W}$. This represents a margin of $55 \%$ when compared to the maximum available power of $10 \mathrm{~W}$.

Table 4: VCHP Cold On-Orbit Cycling Results Summary

\begin{tabular}{|l|c|}
\hline \multicolumn{1}{|c|}{ Item } & Result \\
\hline OB CP average for cold cycle & $-5.7^{\circ} \mathrm{C}$ \\
\hline OB CP Control Band for cold cycle & $\pm 0.1^{\circ} \mathrm{C}$ \\
\hline $\begin{array}{l}\text { Orb Avg Reservoir Heater Power } \\
\text { (10 watts maximum) }\end{array}$ & $4.5 \mathrm{~W}$ \\
\hline Rad Sim C/P max temp & $-23^{\circ} \mathrm{C}$ \\
\hline Rad Sim C/P min temp & $-146^{\circ} \mathrm{C}$ \\
\hline Res Rad Sim C/P max temp & $-23^{\circ} \mathrm{C}$ \\
\hline Res Rad Sim C/P min temp & $-143^{\circ} \mathrm{C}$ \\
\hline Cold plate heat load & $5.0 \mathrm{~W}$ \\
\hline
\end{tabular}

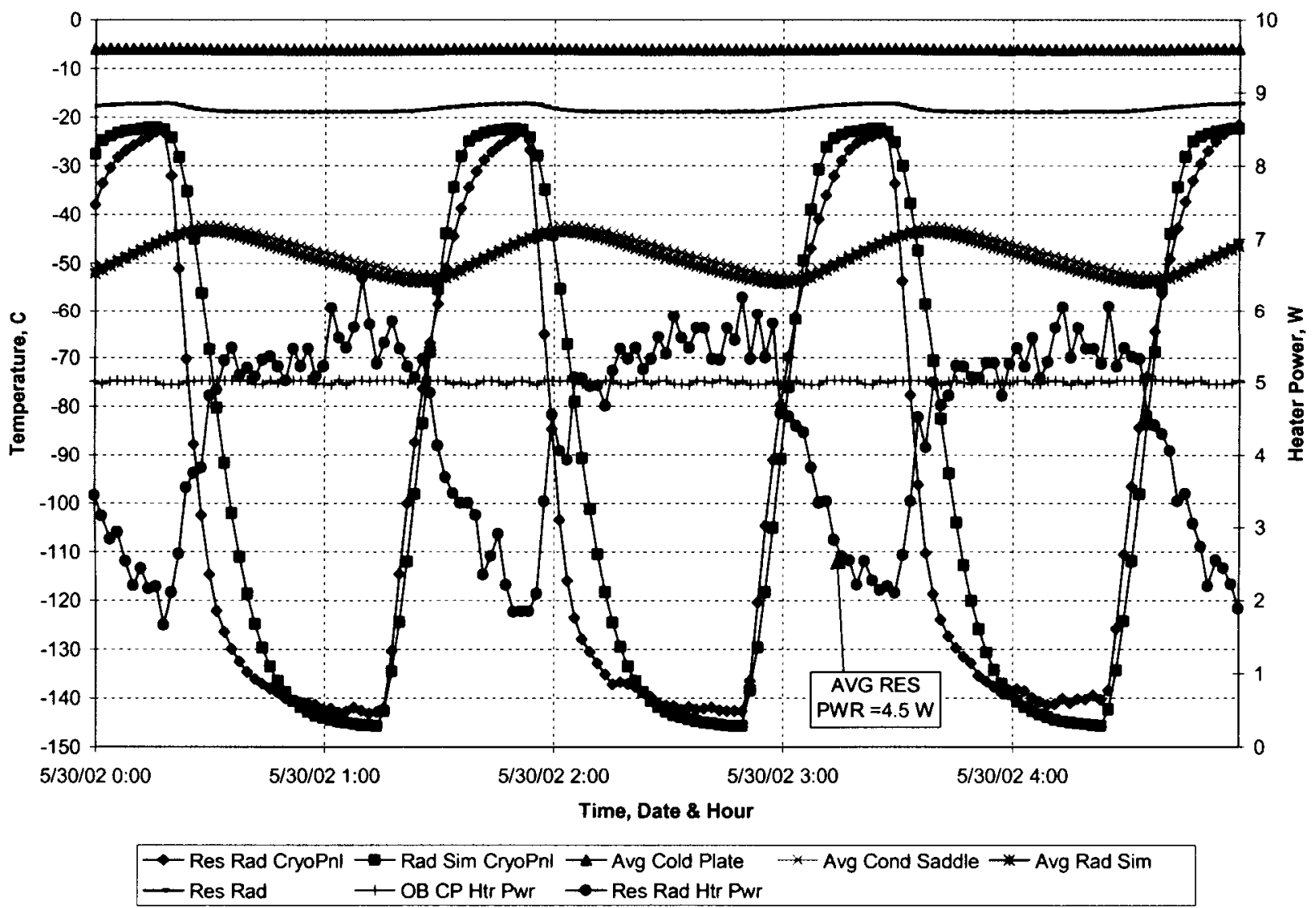


$\because \quad \therefore$

\section{HOT CYCLING RESULTS}

\section{BACKGROUND / PURPOSE}

The Hot Cycling Case was run to demonstrate the control authority of the system when subjected to a simulated hot worst-case orbit-varying sink i.e., time varying sink, with a maximum cold plate heat load of 15 watts. The system success criteria was to maintain the $\mathrm{OBCP}$ average temperature at $-5^{\circ} \mathrm{C} \pm 2^{\circ} \mathrm{C}$.

To simulate the hot on-orbit environment, transient equivalent sink temperatures were generated from the spacecraft environmental flux studies. These were then adjusted to account for the test configuration effects. For the hot case, the temperature goal was to reach approximately $0^{\circ} \mathrm{C}$ to $-160^{\circ} \mathrm{C}$ over a 90 -minute period. Two separate cryopanels were necessary due to the different thermal control coatings on the two radiators.

To achieve the minimum sink temperatures, the TCU's provided chilled gaseous Nitrogen. For the maximum sink temperature levels, cryopanel temperature control was achieved via heated gaseous Nitrogen and test heaters located on the back of the panels.

\section{SUMMARY OF RESULTS}

For the hot cycling test the OBCP heater was operated in flux mode and set to the design load of 15 watts. The VCHP commandable set point was set to $-5^{\circ} \mathrm{C}$ and the reservoir radiator cryopanel and radiator simulator cryopanel were set to $-155^{\circ} \mathrm{C}$ and $-165^{\circ} \mathrm{C}$, respectively. The entire cycling process lasted from 6/3/02 15:37, to $6 / 4 / 02$ 05:29. The goal was to get three repeatable 90 minute cycles.

The initial cycles reflected efforts to cool the OBCP down from the $+20^{\circ} \mathrm{C}$ level used in the previous case and to allow the test team to exercise the cryopanels and system. The focus was to determine the appropriate TCU set points, necessary cryopanel heater values, and the timing of TCU set-point changes. Also, during this period, the VCHP commandable set point was lowered from $-5^{\circ} \mathrm{C}$ to $-7^{\circ} \mathrm{C}$.

The three repeatable cycles started at 6/3/02 22:01 and concluded at 6/4/02 03:01. Figure 8 and Table 5 show key temperature results. As shown, the cryopanel equivalent sink temperatures successfully cycled from $+1.6^{\circ} \mathrm{C}$ to $-143^{\circ} \mathrm{C}$ in a repeatable 90 -minute period. (In Figure 8 , the plot has a lower limit of $-25^{\circ} \mathrm{C}$. This was done to allow for better scaling of the other temperature results). During these three cycles, the reservoir radiator heater power ranged from 0.0 watts to 8.4 watts. As shown, there were brief periods during the orbit peak temperatures when the reservoir radiator heater went to 0.0 watts and the cold plate temperature began to rise. During these temperature rises, the OBCP was not under active control. Since the OBCP temperature was still within the requirements of $-5^{\circ} \mathrm{C} \pm 2^{\circ} \mathrm{C}$, this was not considered a problem.

FIGURE 8. VCHP Hot On-Orbit Cycling Results

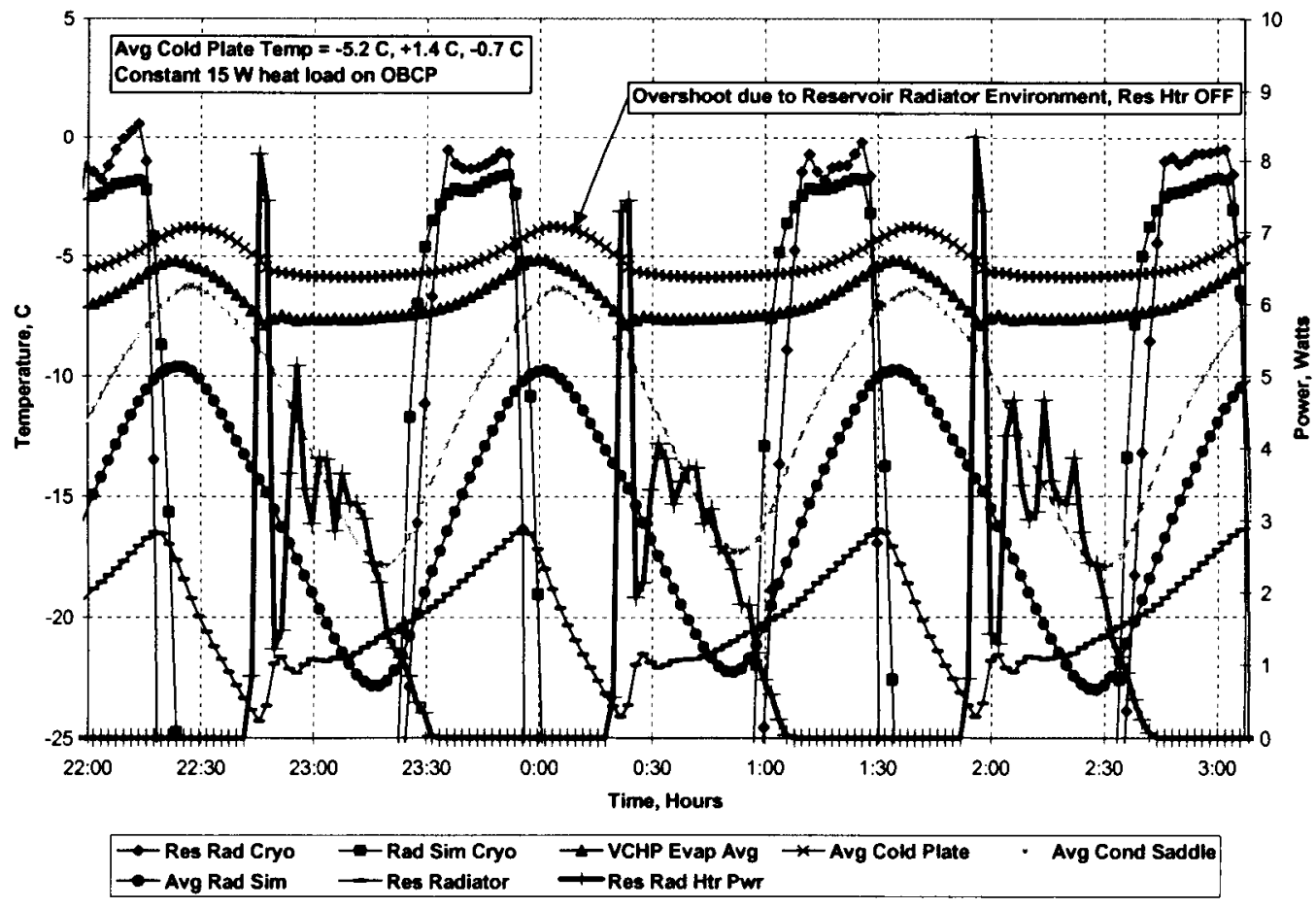


It should be noted, however, that the phenomenon of not being under active heater control was expected. The flight instrument thermal math model (TMM) predicted zero VCHP radiator heater power during the flight hot case peak temperatures and the test confirmed this. The SINDA TMM used a newly developed VCHP subroutine and the test results and flight predictions looked comparable. The post-test effort will include a SINDA model correlation with the steady-state cases.

The orbit average Reservoir Heater power was $1.3 \mathrm{~W}$. This represented a margin of $87 \%$ when compared to the $10 \mathrm{~W}$ available power. As Table 5 indicates, the system maintained the OBCP average temperature within the $5^{\circ} \mathrm{C} \pm 2^{\circ} \mathrm{C}$ requirement.

Table 5: VCHP Hot On-Orbit Cycling Results Summary

\begin{tabular}{|l|l|}
\hline Item & Result \\
\hline OB CP average for hot cycle & $-5.2^{\circ} \mathrm{C}$ \\
\hline OB CP Control Band for hot cycle & $+1.4^{\circ} \mathrm{C},-0.7^{\circ} \mathrm{C}$ \\
\hline $\begin{array}{l}\text { Orb Avg Reservoir Heater Power }(10 \\
\text { watts maximum })\end{array}$ & $1.3 \mathrm{~W}$ \\
\hline Reservoir Heater Power Max \& Min & $8.4 \mathrm{~W}, 0.0 \mathrm{~W}$ \\
\hline Rad Sim C/P max temp & $+1.6^{\circ} \mathrm{C}$ \\
\hline Rad Sim C/P min temp & $-143^{\circ} \mathrm{C}$ \\
\hline Res Rad Sim C/P max temp & $0.6^{\circ} \mathrm{C}$ \\
\hline Res Rad Sim C/P min temp & $-144^{\circ} \mathrm{C}$ \\
\hline Cold plate heat load & $15.0 \mathrm{~W}$ \\
\hline
\end{tabular}

\section{CONCLUSION}

The objective of Cases 5 and 10 was to demonstrate the control authority of the system when subjected to a simulated cold (or hot) worst-case orbit-varying sink i.e., time varying sink, with a minimum (or maximum) cold plate heat load. The system success criteria was to maintain the optical bench cold plate at $-5^{\circ} \mathrm{C} \pm 2^{\circ} \mathrm{C}$.

As outlined in Tables 4 and 5, these objectives have been fully satisfied.

\section{ACKNOWLEDGMENTS}

The authors would like to thank the NASA Goddard Space Flight Center, the Hubble Space Telescope Project, and the Wide Field Camera 3 Project for providing the funding to carry out this work.

Swales Aerospace, Inc. built the Variable Conductance Heat Pipe Assembly as well as the Optical Bench Cold Plate.

\section{REFERENCES}

1. Work Order Authorization (WOA) \#10564, “VCHP Thermal Vacuum Test Preparation and Performance", May 17, 2002.
2. Work Order Authorization (WOA) \#10370 "Fabricate Test WFC3 VCHP TV Test MLI Blankets", April 2, 2002.

3. "HST Wide Field Camera 3 (WFC3) Variable Conductance Heat Pipe (VCHP) Performance Thermal Vacuum Test Plan/Procedure ", Document No. P-442-3022, Rev. A, dated June 2002 by P. Cleveland.

\section{CONTACT}

Paul E. Cleveland, M.S.M.E., M.S.E., P.E.

Energy Solutions International, L.L.C.

8705 Cathedral Way

Gaithersburg, MD 20879-1791

Tel: $\quad 240-631-6660$

Fax: 240-631-6998

PaulCleveland@EnergySolutionsIntl.com

\section{ACRONYMS}

\section{AT Aliveness Test \\ CCHP Constant Conductance Heat Pipe \\ CP Cold Plate \\ EVA Extra Vehicular Activity}

GEVS GSFC Environmental Verification Specification

GSE Ground Support Equipment

GSFC Goddard Space Flight Center

HST Hubble Space Telescope

LN2 Liquid Nitrogen

LVPS Lower Voltage Power Supply

MLI Multi-Layer Insulation

NASA National Aeronautics and Space Administration

OBA Optical Bench Assembly

OBCP Optical Bench Cold Plate

SI Science Instrument

SM Servicing Missions

SM-4 Servicing Mission 4

SS Steady State

T/C Thermocouple

TCM Temperature Control Mode

TCR Temperature Change Request

TCU Temperature Control Unit

T/M Thermistor

TMM Thermal Math Model

TMS Telemetry Monitoring System

TN Thermal Vacuum

VCHP Variable Conductance Heat Pipe

WFC3 Wide Field Camera - 3rd generation

WFPCIIWide Field Planetary Camera II

WOA Work Order Authorization 
$\because \quad \therefore$

\section{APPENDIX}

Figure A-1. Full Setup \& Cold Plate Top Side

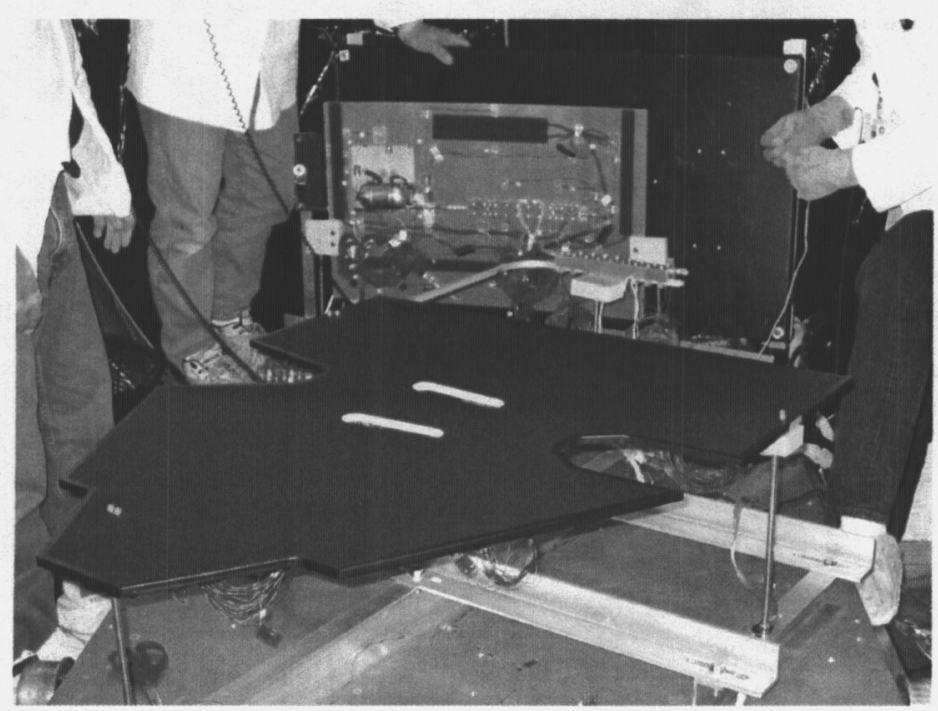

Figure A-2. Radiator Simulator Instrumentation

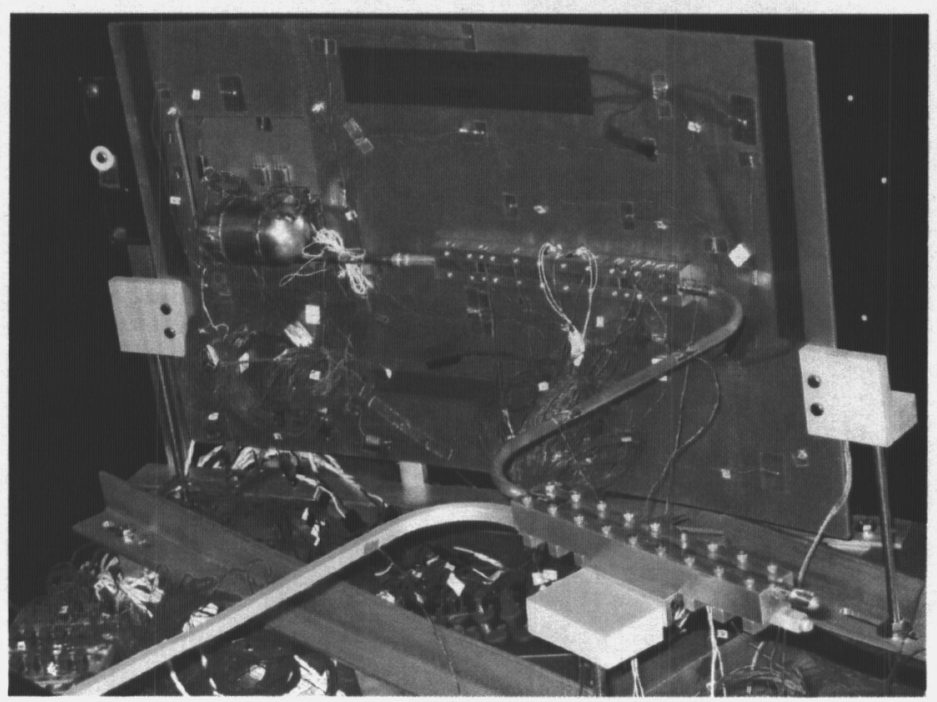

Figure A-3. Radiator Simulator with MLI Closeouts

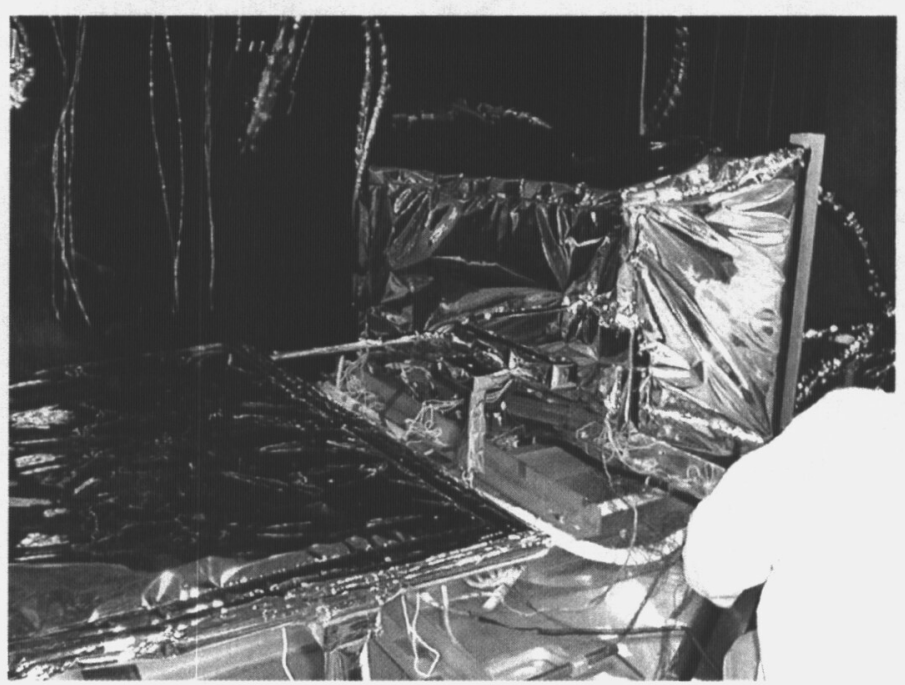

Figure A-4 Test Assembly with MLI

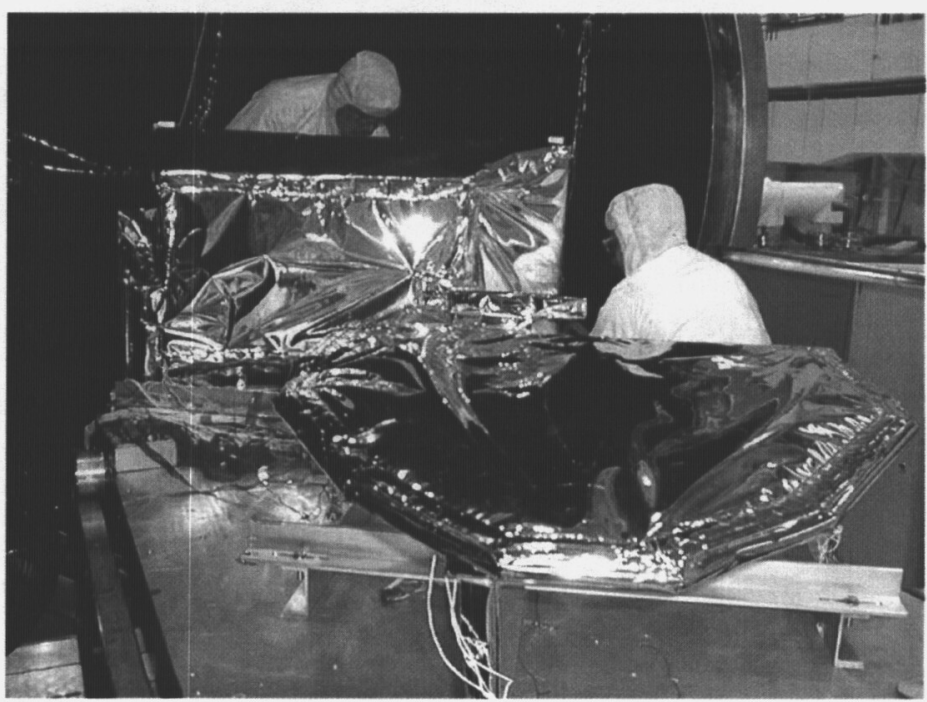

